Original Research Article

\title{
Teratogenicity study in rats of commonly used calcium channel blockers
}

\author{
Sanjay Jaiswal ${ }^{1}$, Davinder Bhardwaj ${ }^{2}$, Dick Brashier ${ }^{1}$
}

${ }^{1}$ Department of Pharmacology,

${ }^{2}$ Department of Obstetrics and Gynaecology, Armed Forces Medical College, Pune, Maharashtra, India

Received: 03 October 2019 Accepted: 11 November 2019

\section{*Correspondence to: Dr. Davinder Bhardwaj, Email: bhardwaj.davinder74@ gmail.com}

Copyright: () the author(s), publisher and licensee Medip Academy. This is an openaccess article distributed under the terms of the Creative Commons Attribution NonCommercial License, which permits unrestricted noncommercial use, distribution, and reproduction in any medium, provided the original work is properly cited.

\begin{abstract}
Background: Calcium channel blockers (CCBs) are popular medicines used to treat hypertension, tachyarrhythmias or angina during pregnancy. Lack of adequate safety data has however created an uncertainty in the use of CCBs in pregnancy. Nifedipine has been reportedly associated with a variety of embryotoxic and fetotoxic effects in animals. Therefore, this study was undertaken to establish whether or not the commonly used CCBs (nifedipine and amlodipine) would produce teratogenic effects in rats.

Methods: Twenty pregnant rats were randomly assigned to each of the treatment and control groups. Nifedipine and amlodipine were used in three dose levels of $5,10,20 \mathrm{mg} / \mathrm{kg}$ and $0.5,1,2 \mathrm{mg} / \mathrm{kg}$ body weight respectively to test its teratogenic effects. The maximum dose of the test drugs used in our study was ten times the maximum recommended human dose. The drugs were administered to the pregnant rats using nasogastric tubes from day 6 through day 15 of pregnancy. The number of live births, stillbirths, litter sizes, crownrump lengths, birth weights and gross abnormalities of the pups delivered were observed and recorded. Skeletal changes and soft tissue changes were also observed in the pups delivered to treated pregnant rats.

Results: It was found that nifedipine and amlodipine did not produce any teratogenic effects in rats at doses 2.5 to 10 times the recommended human dose. None of the pups showed any gross morphological, skeletal or visceral defects.

Conclusions: Nifedipine and amlodipine appear to be safe during pregnancy in therapeutic doses.
\end{abstract}

Keywords: CCBs, Teratogenicity, Rats

\section{INTRODUCTION}

Calcium channel blockers (CCBs) are used in obstetrical practice to treat hypertension, preeclampsia, "haemolysis, elevated liver enzymes and low platelet count" syndrome and preterm labour. However, lack of adequate data has created uncertainty in its use in pregnancy. The US FDA had placed CCBs in category $\mathrm{C}$ of teratogenicity risk meaning that human data is not available and foetal risk is shown in controlled animal studies. Hence, these drugs are justified for use in pregnancy only when the benefits outweigh the potential risk to the foetus and safer alternatives are not available.

Nifedipine has been reportedly associated with a variety of embryotoxic and fetotoxic effects. ${ }^{1}$ Amlodipine is neither embryotoxic nor teratogenic in rats and rabbits upto 2 to 23 times the recommended dose when administered during organogenesis. But rats administered with amlodipine 8 times the maximum recommended human dose (MRHD) for 14 days before mating and throughout gestation had a significant decrease in litter size (by about 50\%) due to fivefold increase in intrauterine deaths. ${ }^{2,3}$

Nifedipine in doses higher than $60 \mathrm{mg}$ per day during human pregnancy has been associated with adverse fetomaternal events as reported from case series. ${ }^{4}$ Yet, in a case-control study, prior exposure to $\mathrm{CCBs}$ in utero did not lead to a higher prevalence of congenital anomalies. ${ }^{5}$ Therefore, experimental studies to test the teratogenic potential of commonly used CCBs become necessary. Rats are the preferred species for teratogenicity studies due to their high fertility and large litter size. 


\section{METHODS}

Healthy young adult virgin female albino rats of inbred homogenous strains and 90-100 days old were used for the study. The animals were kept under normal laboratory conditions in the animal house maintained by the college. Microscopical examination of vaginal smear for cornified epithelial cells in female rats was carried out prior to mating to confirm the oestrous stage of the rats. Healthy active male rats of proven sire were chosen for mating of the animals.

Three female rats in oestrous were housed overnight with a normal male in a cage. Successful mating was confirmed by the presence of a sperm in the vaginal smear. This was considered as day- 1 of pregnancy. The pregnant rats were then caged individually in the animal house.

The teratogenicity study was designed in conformity to the existing regulations and guidelines. ${ }^{6,7}$ Institutional animal ethical committee clearance was obtained from the institute to conduct the study on rodents. Twenty pregnant rats were randomly assigned to each of the treatment and control groups. Nifedipine and amlodipine were used in three dose levels of $5,10,20 \mathrm{mg} / \mathrm{kg}$ and 0.5 , $1,2 \mathrm{mg} / \mathrm{kg}$ body weight respectively to test its teratogenic effects. The maximum dose of the test drugs used in our study was ten times the MRHD. Fresh suspensions in $1 \%$ gum tragacanth of nifedipine and amlodipine each, of 5 $\mathrm{mg} / \mathrm{ml}$ test drug concentration, were prepared for daily oral administration. The drugs were administered to the pregnant rats using nasogastric tubes from day 6 through day 15 of pregnancy to cover the period of organogenesis. The control group of dams were administered $1 \%$ gum tragacanth for the same period of duration as the treated groups. The dams were allowed to deliver normally. The number of live births, stillbirths, litter sizes, crown-rump lengths, birth weights and gross abnormalities of the pups delivered were observed and recorded. The pups were euthanized at birth. Half of these pups were segregated for skeletal examination and the other half for the soft tissue examinations. The dead pups were fixed in $95 \%$ ethyl alcohol, cleared by overnight stay in $2 \% \mathrm{KOH}$ solution, treated with alizarin red stain and preserved in glycerol. ${ }^{8}$ Stained pups were observed under a magnifying glass for assessing skeletal abnormalities. For soft tissue examinations, the pups were fixed in $10 \%$ neutral formalin and dissected for examination of visceral defects and histological slides prepared of heart, liver and kidneys. ${ }^{9}$

Tests of statistical significance were carried out using two sample ' $\mathrm{t}$ ' test for difference in mean values and $\mathrm{p} \leq 0.05$ was considered as significant.

\section{RESULTS}

The results of the teratogenicity studies in pregnant rats are summarised in Table 1 and Figures 1-4. The perinatal data of pregnant rats treated with nifedipine and amlodipine at each of the three drug levels during the gestation period of organogenesis, was compared to that of the control group. The number of drug treated rats who delivered pups was similar to the control group of rats. Hence, the resorption of embryos was similar in all groups.

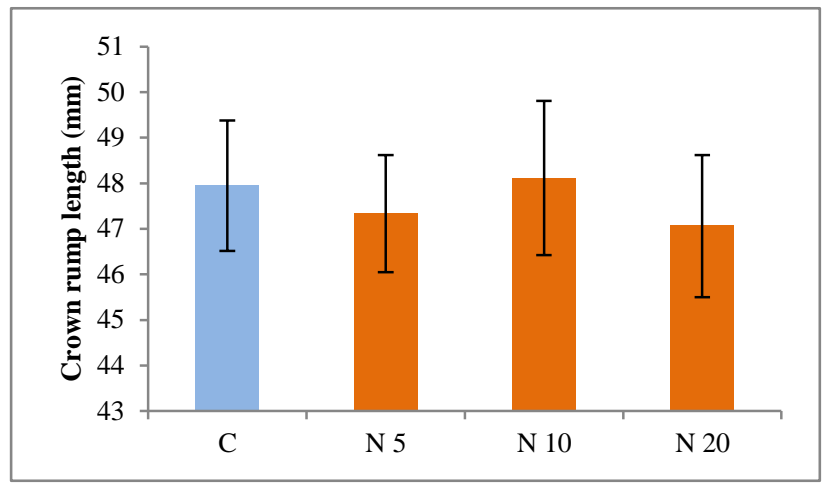

Figure 1: Mean crown rump length of pups delivered to pregnant rats treated with nifedipine vs control. Data represented is mean \pm SD.

$\mathrm{C}=$ Control, N=Nifedipine @ $@ 5,10$ and $20 \mathrm{mg} / \mathrm{kg} / \mathrm{day}$ administered to pregnant rats.

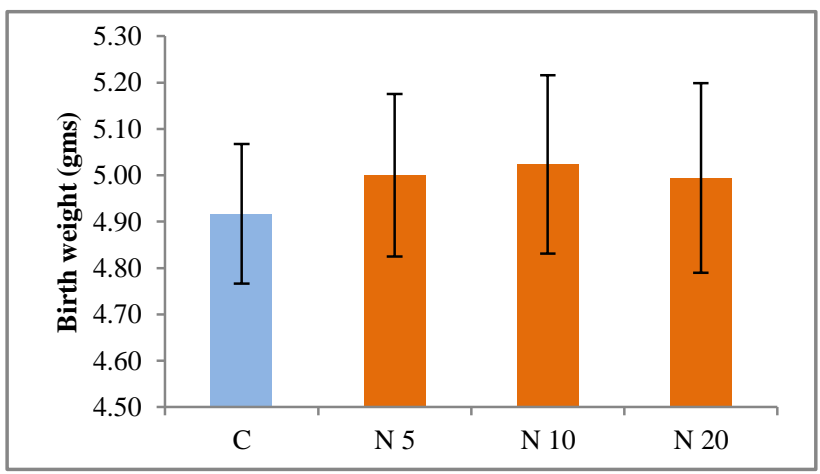

Figure 2: Mean birth weight of pups delivered to pregnant rats treated with nifedipine vs control. Data represented is mean $\pm \mathrm{SD}$.

$\mathrm{C}=\mathrm{C}$ trol, $\mathrm{N}=$ Nifedipine @ 5, 10 and $20 \mathrm{mg} / \mathrm{kg} /$ day administered to pregnant rats.

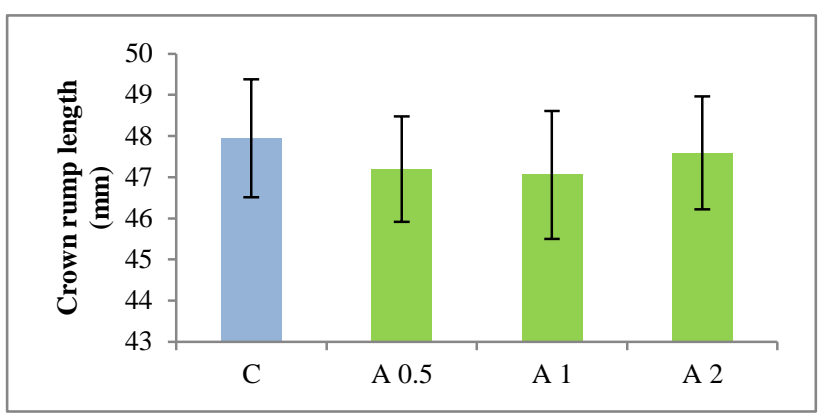

Figure 3: Mean crown rump length of pups delivered to pregnant rats treated with amlodipine vs control. Data represented is mean $\pm \mathrm{SD}$.

$\mathrm{C}=$ Control, A=Amlodipine @ $0.5,1$ and $2 \mathrm{mg} / \mathrm{kg} / \mathrm{day}$ administered to pregnant rats. 
Table 1: Teratogenic effects of nifedipine vs control and amlodipine vs control in pregnant rats ( $\mathrm{n}=\mathbf{2 0})$.

\begin{tabular}{|lllll|}
\hline $\begin{array}{l}\text { Drug } \\
\text { (mg/kg/day) }\end{array}$ & $\begin{array}{l}\text { Number delivered / } \\
\text { Number mated }\end{array}$ & $\begin{array}{l}\text { Mean litter size } \\
\pm \text { SD }\end{array}$ & $\begin{array}{l}\text { Mean number of live } \\
\text { births } \pm \text { SD }\end{array}$ & $\begin{array}{l}\text { Anomalies detected } \\
\text { (gross/visceral/skeletal) }\end{array}$ \\
\hline Control & $18 / 20$ & $8.17 \pm 1.25$ & $7.28 \pm 1.18$ & Nil \\
\hline Nifedipine (5) & $18 / 20$ & $7.67 \pm 1.03$ & $6.56 \pm 0.71$ & Nil \\
\hline Nifedipine (10) & $17 / 20$ & $7.47 \pm 0.94$ & $6.24 \pm 1.2$ & Nil \\
\hline Nifedipine (20) & $17 / 20$ & $6.94 \pm 0.75$ & $5.76 \pm 0.75$ & Nil \\
\hline Amlodipine (0.5) & $20 / 20$ & $8.1 \pm 1.02$ & $7.6 \pm 0.94$ & Nil \\
\hline Amlodipine (1.0) & $18 / 20$ & $7.83 \pm 1.04$ & $7.44 \pm 1.04$ & Nil \\
\hline Amlodipine (2.0) & $17 / 20$ & $8.12 \pm 1.05$ & $7.71 \pm 0.99$ & Nil \\
\hline
\end{tabular}

$\mathrm{SD}=$ Standard deviation.

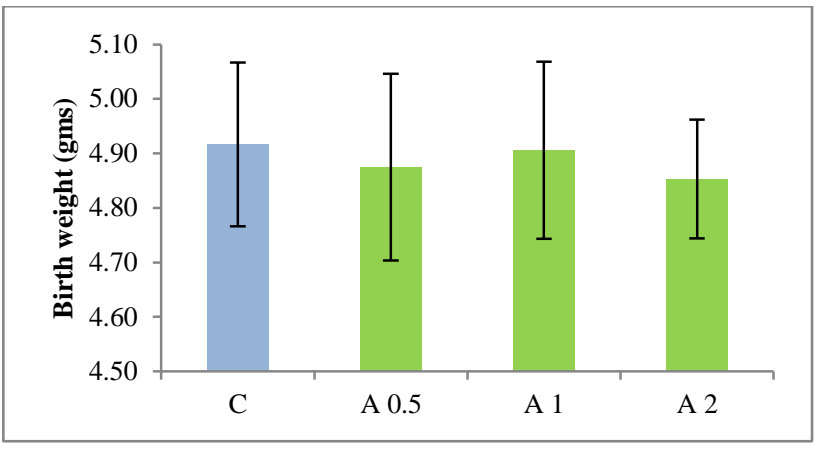

Figure 4: Mean birth weight of pups delivered to pregnant rats treated with amlodipine vs control. Data represented is mean $\pm \mathrm{SD}$.

$\mathrm{C}=$ Control, A=Amlodipine @ $0.5,1$ and $2 \mathrm{mg} / \mathrm{kg} / \mathrm{day}$ administered to pregnant rats.

The difference in mean values between the treated and the control groups, at each level of test drug was not statistically significant, in terms of litter size or number of live births delivered. The mean values of crown- rump length and birth weights of pups delivered was compared between the control and test drug for each of the three dose levels. The difference between the control group and any of the dose levels of the test drugs was not statistically significant. None of the pups showed any gross morphological or skeletal defects as illustrated in Figure 5. Similarly, no visceral defects were detected at any dose level of the CCBs used in the study.

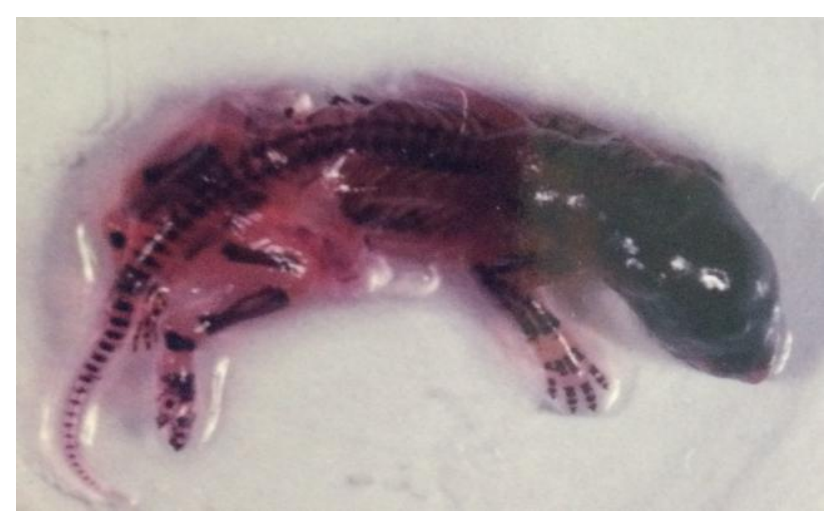

Figure 5: Skeletal examination of a pup delivered using alizarin red stain.

\section{DISCUSSION}

Pharmacotherapy of diseases or disorders during pregnancy has always remained challenging due to the inherent fear of causing harm to the foetus. Yet, medicines cannot be avoided totally in pregnant women and every time the benefits have to be weighed against risks of treatment. It is estimated that the medication use during pregnancy has increased approximately $68 \%$ over the past 30 years in US. ${ }^{10}$ Severe hypertension in pregnancy needs to be treated to prevent the maternal complications. In around 2-8\% of pregnancies across the world, complications of preeclampsia do arise and it is estimated that about $16 \%$ of maternal deaths occur due to complications of hypertension. In US itself, there has been an increase in incidence of preeclampsia by $25 \%$ from 1987-2004. ${ }^{11}$ It is therefore essential and economical to treat gestational hypertension and its complications. Chronic hypertension, diabetes, nulliparity, obesity, maternal age above 35 years and assisted reproductive technology are some of the important risk factors for the development of preeclampsia. ${ }^{11}$ Hypertension is a silent killer and can lead to complications of cardiac failure, coronary artery disease, chronic kidney disease and stroke. Thiazide-like diuretics, CCBs, angiotensin-converting enzyme inhibitors and angiotensin-receptor blockers are the four classes of anti-hypertensives labelled as first-line and later-line drugs in the treatment of hypertension. ${ }^{12}$ Labetalol or hydralazine administered intravenously and immediate release nifedipine are the choices of antihypertensive for urgent blood pressure control in pregnancy. ${ }^{11}$ So, CCBs are effective medicines used to treat hypertension, tachyarrhythmias or angina during pregnancy. In the general population, CCBs are preferred in hypertension either as monotherapy or in combination due to their proven benefits in cardiovascular end-points and total mortality. ${ }^{13}$ However, combination of drugs is best avoided in pregnant women. Also, preclinical studies have not established absolute safety of these drugs during pregnancy. Therefore, this study was undertaken to establish whether or not the commonly used CCBs (nifedipine and amlodipine) would produce teratogenic effects in rats. Further, whereas amlodipine is the most commonly used $\mathrm{CCB}$ in general medical practice, its popularity in obstetrical practice is not to the same extent due to inadequate long term safety studies. There is also 
concern about immediate release nifedipine use and higher mortality in cardiac patients necessitating the popular use of extended release preparations of nifedipine. To be considered teratogenic, a drug should possess the following properties, in that it should result in a characteristic set of malformations, often selective to an organ; to exert its effects at a particular stage of foetal development and to show a dose dependent incidence. ${ }^{14}$

Amlodipine is water soluble but nifedipine is not. Hence, for uniformity of comparison, all drugs were prepared in $1 \%$ gum tragacanth for oral administration. Oral route of administration was used, as is done clinically. The plasma half-lives of nifedipine and amlodipine are 2 hours and 35-50 hours respectively. The MRHD of nifedipine is 2 $\mathrm{mg} / \mathrm{kg} /$ day and that of amlodipine $0.17 \mathrm{mg} / \mathrm{kg} / \mathrm{day}{ }^{1,2}$ Therefore doses in the range 2.5 to 10 times the MRHD were used in the present study on pregnant rats.

The litter size of pups born in the control and treated groups were similar. Though not significant statistically, there was a consistent decrease in litter size with increasing dose of nifedipine. No such observations were seen in the crown-rump length or birth weight of rat pups in any of the treated or control groups. No gross malformations or abnormal locomotor activity were seen in any of the pups delivered. The visceral examinations on gross and histopathological report were also normal in both groups of test drugs. The skeletal examination of the rat pups did not reveal any missing, incomplete or abnormal ossification in any of the groups.

Amongst CCBs, nifedipine has been shown to produce teratogenic effects in rats and rabbits including digital anomalies similar to those reported for phenytoin. Embryotoxicity of nifedipine has been shown in rats at doses 3.5 to 10 times the maxiumum human dose. ${ }^{1}$ Animal studies have also documented that the hypotensive effect of calcium antagonists result in a decrease in uteroplacental blood flow and foetal arterial oxygen content during pregnancy. ${ }^{15}$ Amlodipine has however, not been reported to be teratogenic or embryotoxic in rats and rabbits. ${ }^{2}$ Our studies did not show any teratogenic effects or substantial decrease in litter size of pups for both the CCBs used. This is in conformity to a study on late-pregnant rats where it was shown that nifedipine did not cause teratogenicity or embryotoxicity and birth weights of pups decreased only at doses more than 30 times than usually given. ${ }^{16}$

The US FDA system is the most widely accepted guideline for teratogenic potential of a drug despite its limitations and criticism. In 2015, grouping of teratogenic drugs or biologicals have been modified to elaborate on additional details and is called FDA Pregnancy and Lactation Labelling Rule. ${ }^{17}$ Though CCBs are not major teratogens, the more subtle and long- term adverse consequences cannot be ruled out by available studies. ${ }^{18}$

Limitation of this study was that the doses of CCBs used were normal equivalent doses and not the higher doses to evaluate teratogenic potential. The pregnant rats were allowed to deliver normally whereas caesarean section on day 21 of pregnancy could better reveal embryotoxic effects.

The Society of Obstetricians and Gynaecologists of Canada recommend drug treatment of hypertension in pregnancy with methyldopa, labetalol, beta-blockers or nifedipine to choose from. ${ }^{19}$ Maternal adverse effects of CCBs include tachyardia, palpitations, peripheral oedema, headaches and facial flushing. ${ }^{20}$ A large number of clinical studies suggest that CCBs can be safely given to pregnant women both for long term management of hypertension or for short term treatment of preterm labour. A prospective cohort study of 78 women who took nifedipine during pregnancy showed no increased risk of teratogenicity. ${ }^{21}$ There were no differences in psychosocial and motor effects on children exposed in utero to nifedipine or ritodrine for the management of preterm labour in an another study. ${ }^{22}$ A study on placental vasculature did not show any detrimental effects in uteroplacental or major foetal vessels blood flow with the use of nifedipine to control BP in preeclampsia. ${ }^{23,24}$ In yet another retrospective study of birth outcomes of 231 pregnant women with hypertension, the authors concluded that amlodipine did not appear to be associated with increased rate of foetal malformations compared with other anti-hypertensive medications or maternal hypertension without any drug treatment. ${ }^{25}$ Similarly, a pharmacoepidemiological study did not find any increase in the risk of congenital anomalies due to $\mathrm{CCBs}$ given during pregnancy. $^{26}$ A multicenter prospective observational study of the European Network of Teratology Information Services and other studies have found little association between congenital malformations and CCBs use in early pregnancy. ${ }^{20,27,28}$ Hence, our findings on safety of nifedipine and amlodipine during pregnancy in rats conform to clinical prescribing trends.

\section{CONCLUSION}

In the present study, the differences between the control and treated groups were not statistically significant. It was found that both nifedipine and amlodipine did not produce any teratogenic effects in rats at doses 2.5 to 10 times the recommended human dose. However, complete extrapolation of safety in rodents to human pregnancy would be unreliable. Nevertheless, nifedipine and amlodipine appear to be safe during pregnancy in normal doses.

\section{ACKNOWLEDGEMENTS}

The authors are grateful to the animal handlers of the central animal house and to the Pathology department of the college for the laboratory support.

\author{
Funding: No funding sources \\ Conflict of interest: None declared \\ Ethical approval: The study was approved by the \\ Institutional Ethics Committee
}




\section{REFERENCES}

1. Product Monograph Procardia. Nifedipine. Pfizer Products Inc.

2. Product Monograph Norvasc. Amlodipine besylate. Pfizer Products Inc.

3. Briggs GG, Freeman RK, Yaffe SJ. Drugs in pregnancy and lactation: a reference guide to fetal and neonatal risk. 10th ed. Philadelphia: Lippincott Williams and Wilkins; 2015.

4. Khan K, Zamora J, Lamont RF, Van Geijn H, Svare J, Santos-Jorge C, et al. Safety concerns for the use of calcium channel blockers in pregnancy for the treatment of spontaneous preterm labour and hypertension: a systematic review and metaregression analysis. J Maternal Fetal Neonatal Med. 2010;23(9):1030-8.

5. Sorensen HT, Czeizel AE, Rockenbauer M, Steffensen FH, Olsen J. The risk of limb deficiencies and other congenital abnormalities in children exposed in utero to calcium channel blockers. Acta Obstet Gynecol Scand. 2001;80(5):397-401.

6. Ministry of Health and Family Welfare. Schedule Y The Drugs and Cosmetics Acts and Rules, 1945. India: Governmentt of India; 2016.

7. Animal Welfare Division, Ministry of Environment and Forest, and Climate Change. Compendium of Committee for the Purpose of Control, Supervision of Experiments on Animals. India: Government of India; 2018.

8. Dawson AB. A note on the staining of the skeleton of cleared specimens with alizarin red S. Stain Technol. 1926;1(4):123-4.

9. Wilson JG. Experimental studies on congenital malformations. J Chronic Dis. 1959;10(2):111-30.

10. Mitchell AA, Gilboa SM, Werler MM, Kelley KE, Louik C, Hernández-Díaz S, et al. Medication use during pregnancy, with particular focus on prescription drugs: 1976-2008. Am J Obstet Gynecol 2011;205(1):51.

11. ACOG Practice Bulletin No. 202: Gestational Hypertension and Preeclampsia. Obstet Gynecol. 2019;133(1):e1-e25.

12. James PA, Oparil S, Carter BL, Cushman WC, Dennison-Himmelfarb C, Handler J, et al. 2014 evidence-based guideline for the management of high blood pressure in adults: report from the panel members appointed to the Eighth Joint National Committee (JNC 8). JAMA. 2014;311(5):507-20.

13. Eschenhagen $T$. Treatment of hypertension. In: Brunton LL, Hilal-Dandan R, Knollman BC, eds. Goodman and Gilman's The Pharmacological Basis of Therapeutics. 13th ed. New York: McGraw-Hill Education; 2018: 507-526.

14. Koren G. Special Aspects of Perinatal and Pediatric Pharmacology. In: Katzung BG, editor. Basic and Clinical Pharmacology. 14th ed. New York: McGraw-Hill Education; 2018: 1047-1057.

15. Ridings JE, Palmer AK, Davidson EJ, Baldwin JA. Prenatal toxicity studies in rats and rabbits with the calcium channel blocker diproteverine. Reprod Toxicol. 1996;10(1):43-9.

16. Richichi J, Vasilenko P. The effects of nifedipine on pregnancy outcome and morphology of the placenta, uterus, and cervix during late pregnancy in the rat. Am J Obstetric Gynecol. 1992;167(3):797-803.

17. Brucker MC, King TL. The 2015 US Food and Drug Administration pregnancy and lactation labeling rule. J Midwifery Women's Health. 2017;62(3):308-16.

18. 18. Malha L, August P. Safety of antihypertensive medications in pregnancy: living with uncertainty. $\mathrm{J}$ Am Heart Assoc. 2019;8(15):e013495.

19. Kernaghan D, Duncan AC, McKay GA. Hypertension in pregnancy: a review of therapeutic options. Obstetric Med. 2012;5:44-9.

20. Papatsonis DN, Lok CA, Bos JM, van Geijn HP, Dekker GA. Calcium channel blockers in the management of preterm labor and hypertension in pregnancy. Eur J Obstetrics Gynecol Reprod Biol. 2001;97(2):122-40.

21. Magee LA, Schick B, Donnenfeld AE, Sage SR, Conover B, Cook L, et al. The safety of calcium channel blockers in human pregnancy: a prospective, multicenter cohort study. Am J Obstet Gynecol. 1996;174(3):823-8.

22. Houtzager BA, Hogendoorn SM, Papatsonis DN, Samsom JF, Van Geijn HP, Bleker OP, et al. Longterm follow up of children exposed in utero to nifedipine or ritodrine for the management of preterm labour. BJOG. 2006;113(3):324-31.

23. Rizzo G, Arduini D, Mancuso S, Romanini C. Effects of nifedipine on umbilical artery velocity waveforms in healthy human fetuses. Gynecol Obstet Invest. 1987;24(3):151-4.

24. Moretti MM, Fairlie FM, Akl S, Khoury AD, Sibai BM. The effect of nifedipine therapy on fetal and placental Doppler waveforms in preeclampsia remote from term. Am J Obstet Gynecol. 1990;163(6):18448.

25. Mito A, Murashima A, Wada Y, Miyasato-Isoda M, Kamiya CA, Waguri M, et al. Safety of amlodipine in early pregnancy. J Am Heart Assoc. 2019;8(15):e012093.

26. Davis RL, Eastman D, McPhillips H, Raebel MA, Andrade SE, Smith D, et al. Risks of congenital malformations and perinatal events among infants exposed to calcium channel and beta-blockers during pregnancy. Pharmacoepidemiol Drug Saf. 2011;20(2):138-45.

27. Weber-Schoendorfer C, Hannemann D, Meister R, Eléfant E, Cuppers-Maarschalkerweerd B, Arnon J, et al. The safety of calcium channel blockers during pregnancy: a prospective, multicenter, observational study. Reprod Toxicol. 2008;26(1):24-30.

28. Lennestål R, Olausson PO, Källén B. Maternal use of antihypertensive drugs in early pregnancy and delivery outcome, notably the presence of congenital heart defects in the infants. Eur J Clin Pharmacol. 2009;65(6):615-25.

Cite this article as: Jaiswal S, Bhardwaj D, Brashier D. Teratogenicity study in rats of commonly used calcium channel blockers. Int J Basic Clin Pharmacol 2019;8:2701-5. 